Research Article

\title{
Experimental Study on Mechanical Properties of Deep Buried Granite under Different Confining Pressures
}

\author{
Jun Zhao $\mathbb{D}^{1,2}$ and Tan Zhang ${ }^{1}$ \\ ${ }^{1}$ School of Civil Engineering and Architecture, Anhui University of Science and Technology, Huainan, Anhui 232001, China \\ ${ }^{2}$ School of Civil Engineering, Jiangxi University of Engineering, Xinyu, Jiangxi 338000, China \\ Correspondence should be addressed to Jun Zhao; jzhao_rsm@163.com
}

Received 29 October 2020; Revised 3 November 2020; Accepted 15 November 2020; Published 26 November 2020

Academic Editor: Zhi Cheng Tang

Copyright (c) 2020 Jun Zhao and Tan Zhang. This is an open access article distributed under the Creative Commons Attribution License, which permits unrestricted use, distribution, and reproduction in any medium, provided the original work is properly cited.

\begin{abstract}
Brittle failure of hard rock poses a serious threat to the stability of surrounding rock in deep underground engineering. In order to study the deformation and failure characteristics of deep buried granite under high confining pressure cyclic loading and unloading, MTS815 electro-hydraulic servo rock test system was used to conduct cyclic loading and unloading tests under confining pressures of $15 \mathrm{MPa}, 35 \mathrm{MPa}, 45 \mathrm{MPa}$, and $55 \mathrm{MPa}$, and the corresponding stress-strain curves and deformation failure characteristic curves were obtained. The experimental results show the follows: (1) under the same confining pressure, the peak strength, crack initiation stress, crack damage stress, and Poisson's ratio of the specimens under cyclic loading and unloading are larger than those under conventional triaxial loading and unloading, and the unloading elastic modulus is smaller than that, under conventional triaxial compression; (2) the results show that, under different confining pressures, the granite samples show obvious brittle failure characteristics, the elastic modulus and crack initiation stress increase first and then decrease with the confining pressure, the peak strength and crack damage stress of the samples increase linearly with the confining pressure, and Poisson's ratio increases first and then remains unchanged with the confining pressure; (3) under the two kinds of stress conditions, the macroscopic failure of the samples is mainly shear failure. The deformation and failure law of granite samples revealed in this study has significant reference value for the selection of rock mass mechanical model of surrounding rock stability of underground engineering, the formulation of surrounding rock support countermeasures, and the evolution law of mechanical parameters with damage variables.
\end{abstract}

\section{Introduction}

With the rapid development of the world economy, there has been a rapid increase in demand for energy extraction and underground space development for human survival and development, leading to the large-scale development of human engineering activity in deep underground areas with high stress $[1-3]$. These deep underground projects inevitably encounter a common problem: the surrounding rock mass stability of deep underground structures or structures under high geo-stress. Compared with shallow (low geostress) rock mass, deep rock mass is the carrier of direct interaction between deep resources and underground space development. At depth, the nonlinear behavior of rock mass materials is more prominent, and the in situ stress state of the rock mass and the role of ground stress environment have become more prominent. High stress and large magnitude disasters induced by different engineering activity methods turn out to be more significant [4]. When a cavern is excavated in deep hard rock, the rock mass undergoes complex stress path adjustments due to the interaction of layering, segmental excavation, and excavation between adjacent caverns. The same part of the rock mass is repeatedly subjected to a hoop stress increase and a radial stress decrease (in the direction of the excavation's free face). Once the stress exceeds the ultimate bearing capacity of the surrounding rock itself, a large number of stress-type brittle failures (such as spalling, splitting, and stress-type rock 
burst) may occur, posing a great threat to the surrounding rock stability of underground engineering project and the personal safety of the field technicians. Therefore, examining the deformation and destruction mechanism of deep buried hard rocks under cyclic loading and unloading not only is of great theoretical value but also provides significant engineering guidance.

Many scholars at home and abroad have examined the mechanical properties of deeply buried hard rocks under complex stress paths. Research methods include indoor tests, in situ damage characterization observations, theoretical methods, and numerical simulations, while studies range in scale, covering indoor rock specimens to in situ single chambers to giant cave clusters.

Huang et al. [5] and Martin and Chandler [6, 7] proposed a CWFS model for deep rocks by analyzing the results of indoor tests on a large number of granite mechanical properties. Yang et al. [8], Yin et al. [9], and Yin et al. [10] conducted a large number of cyclic loading and unloading tests on Jinping deep-buried marble specimens and investigated influence factors such as the rate of unloading confining pressure, initial damage, and unloading path on damage characteristics to establish a unified strain energy criterion for homogeneous isotropic hard rocks. Feng et al. [11] examined the Jinping Underground Laboratory Phase 2 deep buried tunnel using digital borehole equipment and proposed a data evaluation method for digital borehole observations based on a rock mass integrity index for analyzing the fracturing process of deep buried hard rock subdivisions. Due to the complexity of stress conditions and uncertainty of the geological and construction conditions at the site, indoor small-scale mechanical tests are still one of the primary methods of studying the mechanical properties of deeply buried hard rocks. The repeated cyclic loading and unloading processes experienced by deep rocks under the influence of multistep/multistage excavations have been simulated by numerous researchers with cyclic loading and unloading tests to study the evolution of rock mechanical properties during this process. For instance, Li et al. [12] studied the mechanical characteristics of sandstone by uniaxial cyclic loading and unloading test combined with micromechanical means. Ming-Qing and Cheng-Dong. [13] and Zhang et al. [14] conducted uniaxial cyclic loading and unloading tests on marble with different specimen categories under the confining pressures of $40 \mathrm{MPa}$. Zhang et al. [15] investigated the destruction mechanism of rocks containing veins in landslide-slip zones under uniaxial cyclic loading and unloading. Wang et al. [16] investigated the strength and deformation characteristics as well as estimated the elastic parameters of Jinping marble under uniaxial compression cyclic loading and unloading. HaoRan et al. [17] studied the damage characteristics of saline rock under multistage cyclic loading and unloading at 5, 10, 15 , and $20 \mathrm{MPa}$ confining pressure. Rui-Dong et al. [18] studied the damage evolution characteristics of coal under triaxial cyclic loading and unloading at 10,15 , and $20 \mathrm{MPa}$ confining pressure. Yang et al. [19] studied the evolution of energy consumption ratio of sandstone under axial cyclic loading at 10,20, and $30 \mathrm{MPa}$ confining pressure. Tang et al. [20] studied the shear strength characteristics of rock mechanics.

In general, the majority of such studies employ uniaxial cyclic loading and unloading tests on soft rocks with relatively low strength, while the confining pressure is low in the triaxial cyclic loading and unloading experimental studies. The high and low confining pressure cyclic replacement environment of deep buried rocks during excavation has not been examined, which makes controlling the surrounding rock mass stability deeply buried or underground structures under high geo-stress difficult. Therefore, further study of the deformation and damage characteristics of hard rocks under various confining pressures and cyclic loading and unloading conditions is an important engineering requirement for deep rock engineering construction.

In this paper, by conducting conventional triaxial and cyclic loading and unloading tests on deep fine-medium grained granite from a hydropower station in Sichuan using a MTS 815 rock testing system at the Institute of Rock and Soil Mechanics, Chinese Academy of Sciences, the strength, deformation, and damage fracture characteristic parameters under low confining pressure to high confining pressure $(0 \sim 50 \mathrm{MPa})$ and cyclic loading and unloading are investigated. The influence of confining pressure on the deformation and damage characteristics of deep-buried hard rocks is analyzed to provide an indoor test basis for excavation support of the deep underground caverns.

\section{Test Conditions and Schemes}

\subsection{Lithological Conditions and Specimen Preparation.} Granitic specimens were sourced from the upper drainage corridor of the underground powerhouse of a hydropower station in Sichuan Province. Specimens were obtained from a depth of $320 \sim 500 \mathrm{~m}$. The following observations are made from the results of SEM scanning (Figure 1) and thin section identification (Table 1). The mineral particle size of the granite is concentrated around $0.3 \sim 4.5 \mathrm{~mm}$, and the mineral components are primarily quartz (40\%), feldspar (50\%), and mica (a minor amount) (Table 1). These specimens are classified as fine-medium grained granite and diorite. Because of the high quartz content, the granite commonly undergoes brittle failure. In situ ground measurements show that the maximum principal stress of the cavern in sampling location is $16 \sim 38 \mathrm{MPa}$. In addition, there is slight rock-core disking in the drilled core (Figure 1); hence, the granite in the test is from a hard rock-high stress environment.

\subsection{Granite Specimens. According to International Society} for Rock Mechanics (ISRM) specifications recommended methods [21], the granite core collected on-site (with a diameter of $70 \sim 72 \mathrm{~mm}$ ) was further processed into $50 \mathrm{~mm}$ diameter and $100 \mathrm{~mm}$ high specimens (Figure 1). In order to reduce the discreteness of the test results, the acoustic velocity of these specimens was measured in the laboratory, and specimens with significant differences in acoustic velocity were rejected. 


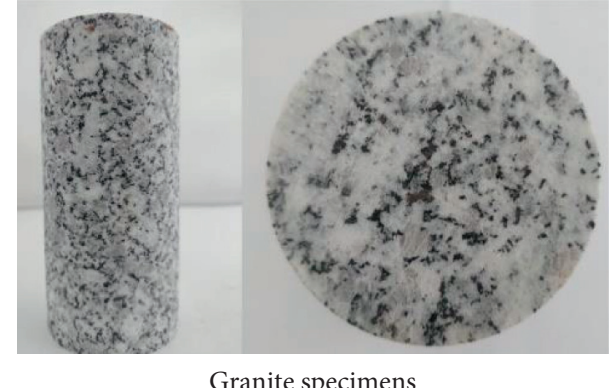

FIGURE 1: Rock core and granite specimens.

TABLe 1: Mineral content and grain size of granite specimens.

\begin{tabular}{lcc}
\hline Name of mineral & Content $(\%)$ & Grain size $(\mathrm{mm})$ \\
\hline Quartz $(\mathrm{Qtz})$ & 36 & $0.30 \sim 5.12$ \\
K-feldspar $(\mathrm{Kfs})$ & 5 & $0.35 \sim 3.13$ \\
Biotite $(\mathrm{Bt})$ & 12 & $0.20 \sim 1.26$ \\
Zircon (Zrn) & 2 & $0.05 \sim 0.12$ \\
\hline
\end{tabular}

2.3. Test Schemes and Procedures. The test was divided into conventional triaxial and triaxial cyclic loading and unloading tests under confining pressures of $15,35,45$, and $55 \mathrm{MPa}$. The test schemes are shown in Table 2. Each confining pressure corresponds to one set of tests with three specimens in each set. All tests were performed under triaxial stress conditions using a MTS 815 rock testing system housed at the Institute of Rock and Soil Mechanics, Chinese Academy of Sciences. The test process in this study included the following steps. First, in order to determine the axial compression design value of the cyclic loading and unloading test $(80 \%$ of the maximum principal stress difference), the peak strength (the maximum principal stress difference) under different confining pressures was obtained using the conventional triaxial compression test; then, the specimen was preloaded to $0.5 \mathrm{kN}$ so that the pressure head is in full contact with the specimen; next, the confining pressure and axial stress were applied to the desired level at a rate of $0.05 \mathrm{MPa} / \mathrm{s}$; after that axial force was applied to $80 \%$ of the maximum principal stress difference at a rate of $0.01 \mathrm{MPa} / \mathrm{s}$ while confining pressure was constant, and the axial force was released (unloaded) to $5 \mathrm{kN}$ a rate of $0.25 \mathrm{kN} /$ s. After repeating the process five times, the specimens were loaded until failure.

\section{Analysis of Test Results}

3.1. Conventional Triaxial Test. Figure 2 shows the stressstrain curves under the conventional triaxial test at $0,15,35$, 45 , and $55 \mathrm{MPa}$ confining pressure. Under various confining pressures, the peak strength, Poisson's ratio, and elastic modulus obtained according to Figure 3 are listed in Table 3. Under various confining pressures, granite specimens immediately show a significant stress drop with increasing strain after reaching the peak strength, and the peak strain ranges from $0.65 \%$ to $1.19 \%$ (less than 3\%) (Figure 2). According to the classification in the literature [22], the specimens experience brittle failure. According to the data in Table 3, we plot the relation curves between peak strength, elastic strength, Poisson's ratio, and confining pressure for the conventional triaxial tests (Figure 4). The peak specimen strength increases linearly with confining pressure (Figure 4(a)). The elastic modulus increases first and then decreases with confining pressure, and under a confining pressure of $45 \mathrm{MPa}$, the elastic modulus reached a maximum $61.3 \mathrm{GPa}$ (Figure 4(b)). When confining pressure is less than $25 \mathrm{MPa}$, Poisson's ratio increases with confining pressure. When the confining pressure is greater than $25 \mathrm{MPa}$, Poisson's ratio is $19.6 \times 10^{-2}$ (Figure $4(\mathrm{~b})$ ).

3.2. Cyclic Loading and Unloading Test. In the cyclic loading and unloading test, the elastic modulus is calculated using the mean unloading elastic modulus. The unloading elastic modulus $\left(E_{\mathrm{ur}}\right)$ equals the slope at two intersecting points of the hysteresis loop:

$$
E_{\mathrm{ur}}=\frac{\Delta\left(\sigma_{1}-\sigma_{3}\right)}{\Delta \varepsilon_{1}}
$$

where $\Delta\left(\sigma_{1}-\sigma_{3}\right)$ is the increment of axial stress at both ends of the hysteresis loop; $\sigma_{1}$ is the axial stress; $\sigma_{3}$ is the confining pressure; and $\Delta \varepsilon_{1}$ is the increment of axial strain at both ends of the hysteresis loop.

According to the ratio of lateral strain to axial strain during unloading and reloading, Poisson's ratio $(\mu)$ under this cyclic loading and unloading is obtained, which is called the ratio of lateral strain increment and axial strain increment at the two intersection points of the hysteresis loop:

$$
\mu=\frac{\varepsilon_{3 u}-\varepsilon_{3 s}}{\varepsilon_{1 u}-\varepsilon_{1 s}}
$$

where $\varepsilon_{3 u}-\varepsilon_{3 s}$ is the lateral strain increment at the two intersection points of the hysteresis loop and $\varepsilon_{1 u}-\varepsilon_{1 s}$ is the axial strain increment at the two intersection points of the hysteresis loop.

Figure 3 shows the stress-strain curves of the specimens tested under the confining pressures of $0,35,45$, and $55 \mathrm{MPa}$. With increasing confining pressure, the plastic deformation stage of the granite increases, and the axial stress-strain curves of the granite specimen under cyclic loading and unloading are concavely curved and closely arranged (Figure 3). At the beginning of cyclic loading and unloading, five hysteresis loops are generated. The area of the hysteresis loops increases with the hysteresis loop. In the lateral stressstrain curve, the hysteresis loop area also increases; however, the shape of the hysteresis loop is convex. Rock specimens under cyclic loading and unloading immediately show significant stress drop after reaching the peak strength, and the peak strain ranges from $0.56 \%$ to $1.24 \%$ (less than $2.6 \%$ ), which is brittle failure $[23,24]$.

The peak strength of specimens is listed in Table 4, and the curve of peak strength vs. confining pressure is plotted (Figure 5(a)). The unloaded elastic modulus and Poisson's ratio are obtained according to equations (1) and (2) and Figure 4 (Tables 5 and 6). In addition, the curves of unloaded elastic modulus vs. Poisson's ratio and confining pressure 
TABLE 2: Test schemes.

\begin{tabular}{lcr}
\hline Name of test & Confining pressure (MPa) & Specimen \\
\hline & 0 & JZ-0-1, JZ-0-2, JZ-0-3 \\
Conventional triaxial test & 15 & JZ-15-1, JZ-15-2, JZ-15-3 \\
& 35 & JZ-35-1, JZ-35-2, JZ-35-3 \\
& 45 & JZ-45-1, JZ-45-2, JZ-45-3 \\
& 55 & XHJ-55-1, JZ-55-2, JZ-55-3, XHJ-0-2, XHJ-0-3 \\
\hline & 0 & XXJ-15-1, XHJ-15-2, XHJ-15-3 \\
Triaxial cyclic loading and unloading test & 15 & XHJ-35-1, XHJ-35-2, XHJ-35-3 \\
& 35 & XHJ-45-1, XHJ-45-2, XHJ-45-3 \\
& 45 & XHJ-55-1, XHJ-55-2, XHJ-55-3 \\
\hline
\end{tabular}

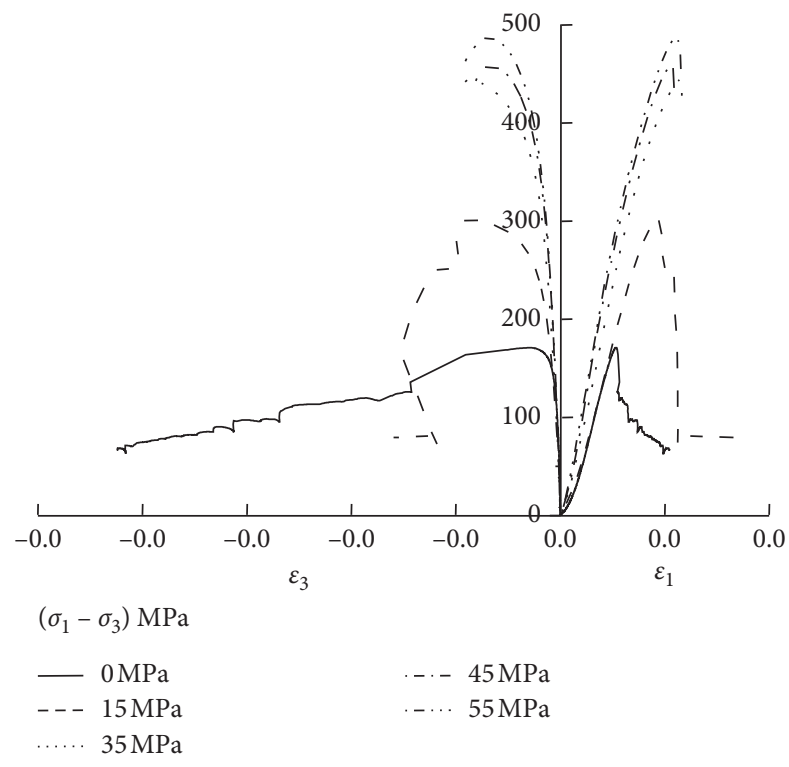

Figure 2: Stress-strain curves for conventional triaxial tests.

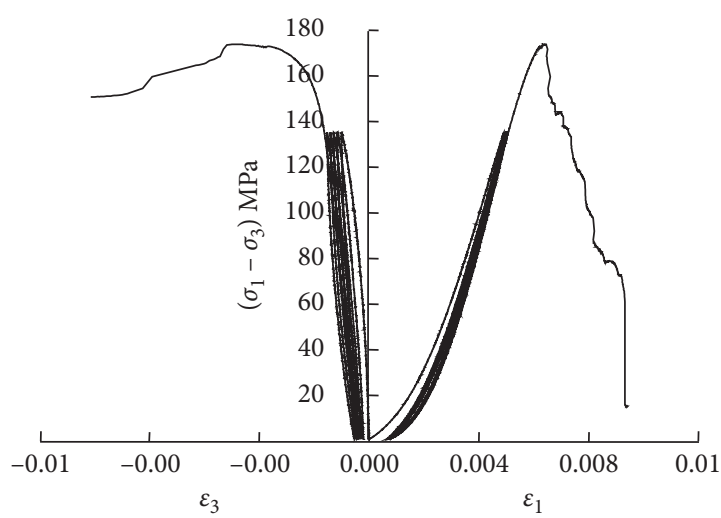

(a)

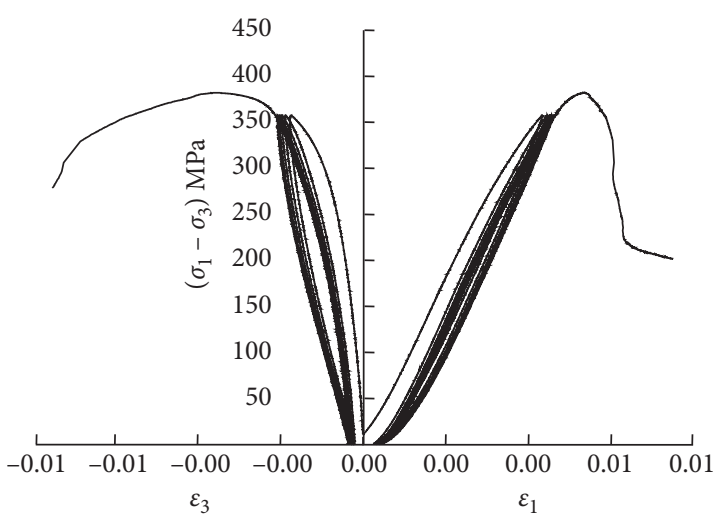

(b)

FIGURE 3: Stress-strain curves of triaxial cyclic loading and unloading tests with varying confining pressures. (a) The confining pressure is $0 \mathrm{MPa}$. (b) The confining pressure is $30 \mathrm{MPa}$.

are plotted according to the data in Tables 5 and 6 (Figure 5(b)). Under cyclic loading and unloading, the peak strength of specimens increases with increasing confining pressure (Figure 5). Peak strength is linearly related to confining pressure in general, which is the same as the relationship between peak strength and confining pressure under conventional triaxial conditions. The elastic modulus increases first and then decreases with confining pressure. 
TABLE 3: Conventional triaxial peak strength under various confining pressures.

\begin{tabular}{lcccc}
\hline Confining pressure $(\mathrm{MPa})$ & Peak strength $(\mathrm{MPa})$ & Axial peak strain $\left(10^{-3}\right)$ & Elastic modulus $(\mathrm{GPa})$ & Poisson's ratio $\left(10^{-2}\right)$ \\
\hline 0 & 171.1 & 5.3 & 41.4 & 7.1 \\
15 & 330.3 & 11.4 & 38.0 & 13.1 \\
35 & 504.3 & 14.1 & 52.3 & 26.2 \\
45 & 523.2 & 12.7 & 68.1 & 19.9 \\
55 & 566.1 & 10.3 & 56.1 & 23.2 \\
\hline
\end{tabular}

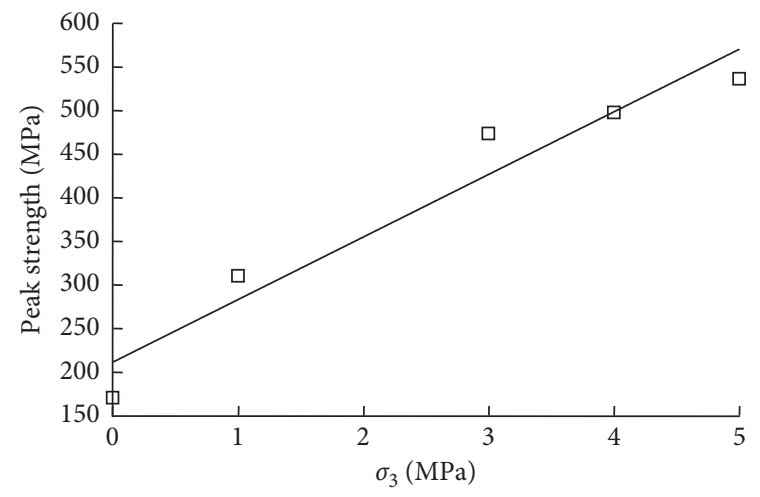

(a)

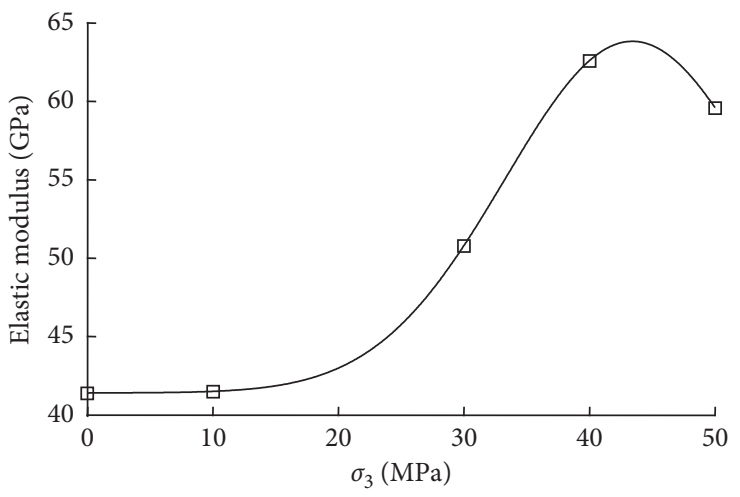

(b)

Figure 4: Relationship between peak strength, elastic strength, Poisson's ratio, and confining pressure in conventional triaxial tests. (a) Peak strength vs. confining pressure. (b) Elastic modulus vs. confining pressure.

TABLE 4: Peak strength of cyclic loading and unloading under different confining pressures.

\begin{tabular}{lcc}
\hline Confining pressure $(\mathrm{MPa})$ & Peak strength $(\mathrm{MPa})$ & ${\text { Axial peak strain }\left(10^{-3}\right)}^{5}$ \\
\hline 0 & 171.8 & 7.9 \\
15 & 362.0 & 12.3 \\
35 & 425.3 & 12.9 \\
45 & 554.1 & 14.1 \\
55 & 585.9 & 1 \\
\hline
\end{tabular}

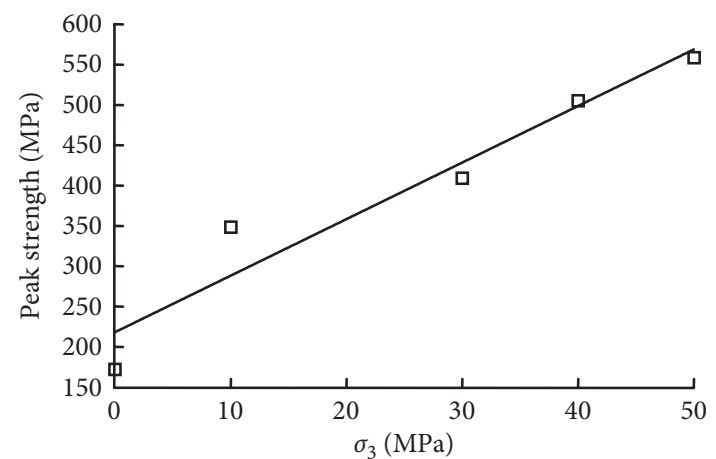

ㅁ Value of test

Line of fitting

(a)

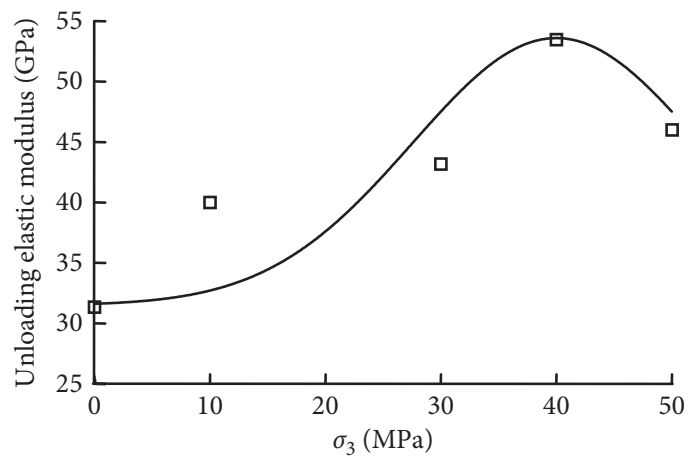

口 Value of test

- Equation (1)

FIGURE 5: Relationships between peak strength, unloading elastic modulus, Poisson's ratio, and confining pressure under cyclic loading and unloading. (a) Peak strength vs. confining pressure. (b) Unloading elastic modulus vs. confining pressure. 
TABLE 5: Unloading elastic modulus of hysteresis loops under various confining pressures.

\begin{tabular}{lccccc}
\hline \multirow{2}{*}{$\begin{array}{l}\text { Category of confining pressure } \\
(\mathrm{MPa})\end{array}$} & Hysteresis loop & Hysteresis loop & Hysteresis loop & Hysteresis loop & Hysteresis loop \\
& 1 & 2 & 3 & 4 & 5 \\
\hline 0 & 32 & 31 & 31 & 31 & 32 \\
15 & 46.2 & 43.1 & 41.3 & 42.3 & 42 \\
35 & 46.9 & 47.6 & 48.9 & 46.2 & 40.1 \\
45 & 60.1 & 58 & 58.6 & 59 & 48 \\
55 & 51.6 & 49.9 & 51.1 & 51.1 & 59.1 \\
\hline
\end{tabular}

TABLE 6: Poisson's ratio of hysteresis loops under various confining pressures.

\begin{tabular}{|c|c|c|c|c|c|c|}
\hline \multirow{2}{*}{$\begin{array}{l}\text { Category of confining pressure } \\
(\mathrm{MPa})\end{array}$} & \multicolumn{6}{|c|}{ Poisson's ratio $\left(10^{-2}\right)$} \\
\hline & $\begin{array}{c}\text { Hysteresis loop } \\
1\end{array}$ & $\begin{array}{c}\text { Hysteresis loop } \\
2\end{array}$ & $\begin{array}{c}\text { Hysteresis loop } \\
3\end{array}$ & $\begin{array}{c}\text { Hysteresis loop } \\
4\end{array}$ & $\begin{array}{c}\text { Hysteresis loop } \\
5\end{array}$ & Average \\
\hline 0 & 17.3 & 19.8 & 21.1 & 22.6 & 23.2 & 21.0 \\
\hline 15 & 29.1 & 30.2 & 30.1 & 29.5 & 31.2 & 28.6 \\
\hline 35 & 41.3 & 42.0 & 44.3 & 44.6 & 44.3 & 42.3 \\
\hline 45 & 29.1 & 29.2 & 29.1 & 28.1 & 27.9 & 26.5 \\
\hline 55 & 21.3 & 21.3 & 21.5 & 21.3 & 21.6 & 21.3 \\
\hline
\end{tabular}

Under a confining pressure of $45 \mathrm{MPa}$, the elastic modulus reaches a maximum of $52.2 \mathrm{GPa}$. Poisson's ratio also increases first and then decreases with confining pressure under cyclic loading and unloading. Under a confining pressure of $35 \mathrm{MPa}$, the elastic modulus reaches a maximum of $36.3 \times 10^{-2}$. In a single specimen, the axial strain increment of the hysteresis loops slightly increases with the hysteresis loop under cyclic loading and unloading. For instance, under a confining pressure of $35 \mathrm{MPa}$, the strain increment of the hysteresis loops are $8.01 \times 10^{-3}$, $8.12 \times 10^{-3}, 8.33 \times 10^{-3}, 8.34 \times 10^{-3}$, and $8.08 \times 10^{-3}$, respectively; however, the axial stress increment remains nearly unchanged. Therefore, the unloading elastic modulus is slightly reduced or almost same. Due to the fact that the granite is taken from a tight hard rock under high geo-stress, the loading and unloading hysteresis loop is long and narrow, and the accretion effect of the rock density is limited under the cyclic loading and unloading stress path.

The variation range of Poisson's ratio gradually decreases, and this trend becomes more significant under high confining pressure. For instance, under a confining pressure of $45 \mathrm{MPa}$, Poisson's ratio of hysteresis loops 1 to 5 are $27.5 \times 10^{-2}, \quad 29.3 \times 10^{-2}, \quad 27.8 \times 10^{-2}, 25.8 \times 10^{-2}$, and $27.8 \times 10^{-2}$, respectively. This is because the damage of specimens under cyclic loading and unloading increases with increasing hysteresis loops, which causes the hoop strain to increase with increasing damage. Since the inhibiting ability of the hoop strain is poor under low confining pressure, Poisson's ratio increases significantly with the hysteresis loop under low confining pressure. However, the high confining pressure has a stronger ability to restrain hoop strain. As a result, Poisson's ratio changes less under high confining pressure cycles.

\section{Comparative Analysis of Conventional Triaxial and Cyclic Loading and Unloading Tests}

4.1. Mechanical Parameters. Under the same confining pressure, the peak strength of specimens in the cyclic loading and unloading tests is generally larger the corresponding specimens in conventional triaxial tests, which is caused by the greater degree of microfracture closure in the rock under cyclic loading and unloading than under conventional triaxial testing, resulting in greater frictional strength under loading and unloading. The unloading elastic modulus of specimens in the cyclic loading and unloading tests is generally smaller than those in conventional triaxial tests, due to the fact that the hysteresis loop under cyclic loading and unloading is convex. Furthermore, Poisson's ratio of specimens in the cyclic loading and unloading tests is larger than those in conventional triaxial tests because compared to the conventional triaxial unidirectional loading process repeated loading and unloading of the rock specimen under cyclic loading and unloading intensifies the closure, extension, and aggregation of the pre-existing fractures in the specimen, as well as the formation of induced fractures and increases the damage degree. There is a significant cumulative damage effect under cyclic loading and unloading on the mechanical properties of such rocks, indicating that we must consider the effect of cracking on rock mass mechanical parameters caused by cumulative damage under 
stage excavation when we analyze the surrounding rock mass stability of underground structures under high geostress.

4.2. Volumetric Strain Characteristics. The similarities and differences in volumetric strain characteristics of specimens under conventional triaxial and cyclic loading and unloading tests with the deviatoric stress-volume strain curves at $50 \mathrm{MPa}$ confining pressure are discussed. Under the two stress paths, the curves can be divided into two parts, the volume decrease stage and volume increase stage. That is, when the external load is small, microcracks inside the rock close gradually with increasing external load; hence, the rock volume decreases. When the external load is greater than critical load, microcracks inside the rock splay gradually with increasing external load, causing rock volume to increase until failure. Under the conventional triaxial and cyclic loading and unloading paths, points $\mathrm{A}$ and $\mathrm{B}$ represent the demarcation points of the two stages, respectively (namely, the maximum point of volume strain). Under the same conditions, the relative increment from the deviatoric stress at the inflection point of volume strain to the peak deviatoric stress in the conventional triaxial test is 0.22 (the difference between the peak deviatoric stress and the deviatoric stress at the inflection point of volume strain/ the deviatoric stress at the inflection point of volume strain), while the corresponding increment in the cyclic loading and unloading test is only 0.18 . In contrast to the conventional triaxial test, the cumulative damage of specimens in the cyclic loading and unloading test under the same volume strain is larger, restricting the specimen from bearing a larger load increment after reaching the peak volume strain, indicating that, under the same conditions, the bearing potentials of hard surrounding rocks that have undergone multiple stress adjustments are much smaller than those of hard surrounding rocks that have experienced fewer stress adjustments after an external load exceeds its damage stress. Therefore, it is necessary to systematically analyze the stress evolution law and damage degree of the hard surrounding rock under the condition of high stress layered or segmented excavation to estimate its bearing potential and select reasonable reinforcement means and timing.

4.3. Crack Initiation Stress and Crack Damage Stress. The volumetric strain is the sum of the elastic volumetric strain and the crack volumetric strain. When the volumetric strain is positive, the volume is decreasing. In the elastic stage, the total volumetric strain increment is equal to the elastic volumetric strain increment. At this moment, the initial crack is closed, and the initial crack volumetric strain is equal to the volumetric shrinkage of the initial crack closure. When the specimen enters the crack growth stage, the volumetric strain increment of the crack propagation is contained in the total volumetric strain increment, so the total volumetric strain increment is less than the elastic strain increment. Hence, the crack volumetric strain curve inclines toward the negative direction and there is an inflection point. The axial stress level corresponding to this inflection point is the crack stress. When the load increases continuously, the volume deformation of the rock shifts from compression to expansion, and an inflection point will appear in the volumetric strain curve. The axial stress level corresponding to this inflection point is the damage stress. In the conventional triaxial test results, stress values corresponding to the inflection points of the axial strain-volumetric strain curve and the axial strain-crack volumetric strain curve are the initial stress and damage stress, respectively (Figure 6). In the cyclic loading and unloading test results, the stress value corresponding to the inflection point of the axial strain-crack volumetric strain first loading curve on the stress-strain curve is the initial stress, and the stress value corresponding to the inflection point of the axial strain-volumetric strain of the final loading curve on the stress-strain curve is the damage stress (Figure 6). The initial stress and damage stress of specimens under various confining pressures in conventional triaxial and cyclic loading and unloading tests are obtained (Table 7).

According to the data in Table 6, the curves among the crack initiation stress, damage stress, and confining pressure are further plotted (Figure 7). Under conventional triaxial and cyclic loading and unloading tests, the crack initiation stress of the specimen increases first and then decreases with confining pressure (Figure 7). Under a $35 \mathrm{MPa}$ confining pressure, the crack initiation stress reaches $139.4 \mathrm{MPa}$ and 240.5 MPa, respectively. Under the two stress paths, the crack damage stress of the specimens increases linearly with confining pressure. From the slope of the fitting curve, we can see that the crack damage stress increment of specimens in the cyclic loading and unloading tests is generally larger than that in conventional triaxial tests. When the external load is less than the crack damage stress, the closure degree of microfractures in the rock under cyclic loading and unloading is greater than that under conventional triaxial loading. The contact area of microfractures in the rock under cyclic loading and unloading is greater than that under conventional triaxial loading. Therefore, the frictional strength under cyclic loading and unloading is greater than that under conventional triaxial loading, which causes the crack initiation stress and crack damage stress of specimens in the cyclic loading and unloading tests to be generally larger than those in conventional triaxial tests under the same confining pressure.

4.4. Macrofailure Characteristics. The macrofailure characteristics of specimens under different confining pressures in the conventional triaxial test are shown in Figure 8. The macrofracture behavior of the granite specimen is shear fracture. Under a $0 \mathrm{MPa}$ confining pressure, there are three primary tensile cracks accompanied by a few secondary cracks, and the damage is relatively serious. Under a $15 \mathrm{MPa}$ confining pressure, a tension-shearing crack intersects the specimen surface, the amount of secondary cracks decreases, and only a few cracks exist. Under a $35 \sim 55 \mathrm{MPa}$ confining pressure, only one complete shear crack passes through the upper and lower surfaces of the granite, showing a wedge shape from $45^{\circ}$ to $65^{\circ}$ with no secondary cracks. Under cyclic 


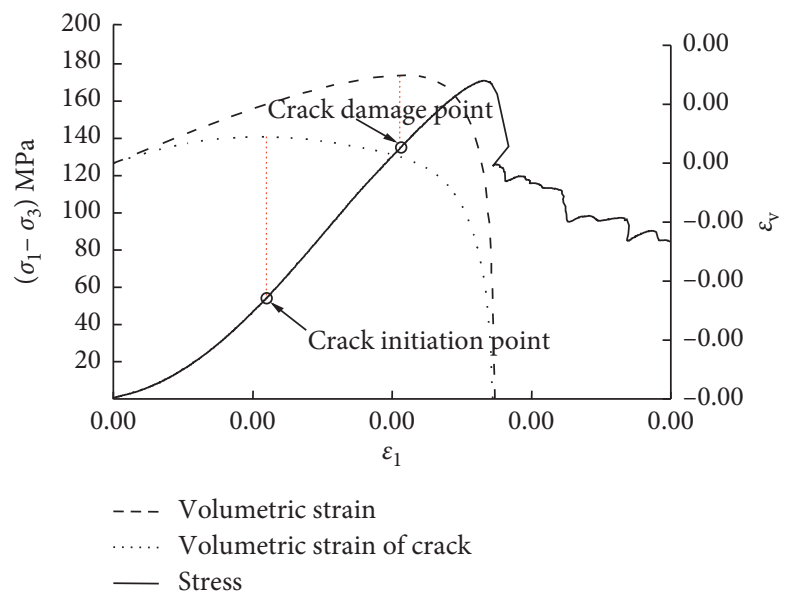

FIgURE 6: Determination of crack initiation stress and crack damage stress.

TABLE 7: Crack initiation stress and crack damage stress under various confining pressures.

\begin{tabular}{lcccc}
\hline $\begin{array}{l}\text { Confining pressure } \\
(\mathrm{MPa})\end{array}$ & \multicolumn{2}{c}{ Conventional triaxial test } & \multicolumn{2}{c}{$\begin{array}{c}\text { Cyclic loading and unloading test } \\
\text { Crack damage stress } \\
(\mathrm{MPa})\end{array}$} \\
\hline 0 & Crack initiation stress (MPa) & Crack damage stress (MPa) & Crack initiation stress (MPa) & 132.3 \\
15 & 58.2 & 125.1 & 58.3 & 181.6 \\
35 & 75.6 & 167.9 & 28.6 & 322.1 \\
45 & 98.3 & 291.5 & 142.2 & 376.2 \\
55 & 89 & 339.2 & 140.2 & 449.5 \\
\hline
\end{tabular}

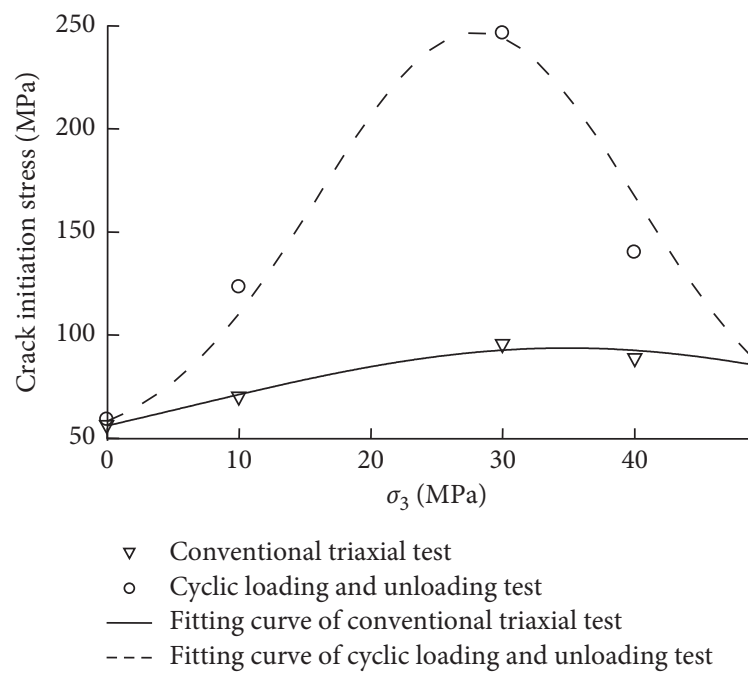

FIgURE 7: Relationship between crack initiation stress, crack damage stress, and confining pressure.

loading and unloading, when the confining pressure is $0 \mathrm{MPa}$, the damage to the specimen was relatively serious. Most specimens experience damage with a few shear cracks; however, different from the conventional triaxial test, shear cracks with complete transfixion were dominant under 15, 35 , and $55 \mathrm{MPa}$ confining pressures, accompanied by a few secondary cracks. Under a $45 \mathrm{MPa}$ confining pressure, there exists a mesh of cracks dominated by shear cracks with complete transfixion and supplemented by a secondary shear crack. Moreover, tension cracks are present. Since most of the microcracks in the rock are oblique cracks and a few of the microcracks are transverse cracks, some of the oblique cracks in the rock will slip and expand with increasing axial stress under low confining pressure, which causes tensional stress to concentrate and partial tensional cracks to appear. Under high confining pressure, due to the 


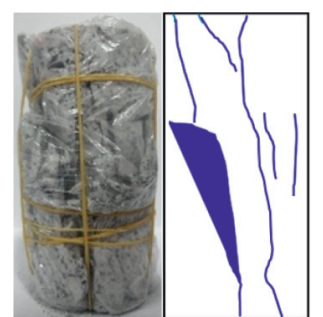

(a)

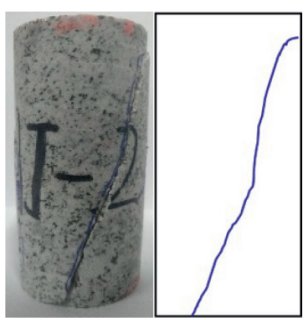

(b)

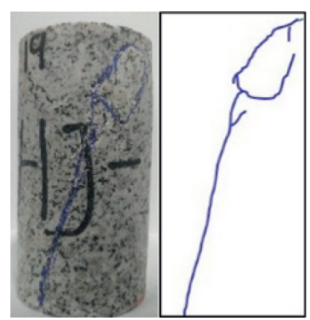

(c)

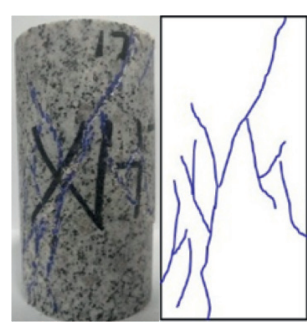

(d)

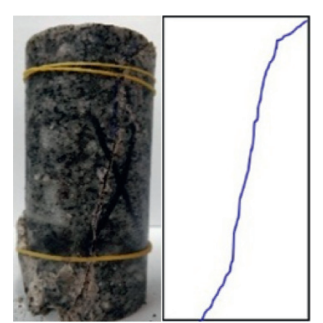

(e)

Figure 8: Failure characteristics of specimens under various confining pressures.

fact that the tensional stress is less than or equal to the external confining pressure on the rock, these oblique cracks can only develop along the original crack direction and finally connect to form a shear crack running through the upper and bottom portions of the specimen.

In general, under the high stress paths, macroscopic failure of the granite specimens is primarily shear failure, indicating that the supporting measures for deep failure of the complete surrounding rock in the deep-buried underground cavern under high ground stress should be primarily designed to prevent shear failure. Reducing the loose cave surrounding rock and increasing the number of systematic bolts with reasonable distance and length is an effective measure to enhance surrounding rock shear strength.

\section{Conclusions}

In order to study the deformation and failure characteristics of deeply buried granite under high confining pressure triaxial cyclic loading and unloading, we carried out conventional triaxial and cyclic loading and unloading tests on the granite specimens under the various confining pressures, obtained corresponding stress-strain curves as well as characteristics of macroscopic deformation and failure, and comparatively studied the similarities and differences in the deformation and failure laws.

The primary conclusions are as follows:

(1) Under the two stress paths, the peak strength of the specimens linearly increases with increasing confining pressure. The elastic modulus increases first and then decreases. Under a certain confining pressure, the elastic modulus reaches the maximum value. When the confining pressure is less than a certain value, Poisson's ratio increases with increasing confining pressure. When confining pressure is greater than the value, Poisson's ratio remains unchanged or decreases with confining pressure. The crack initiation stress increases first and then decreases with confining pressure, while the crack damage stress increases linearly with confining pressure.

(2) Under the same confining pressure, the peak strength, crack initiation stress, crack damage stress, and Poisson's ratio of specimens in the cyclic loading and unloading tests are generally larger than those in conventional triaxial tests, while the unloading elastic modulus is smaller than that in conventional triaxial tests. The results reveal that cyclic loading and unloading has a significant strengthening effect on the frictional strength of rock and has a significant cracking effect on deformation parameters.

(3) The macroscopic failure characteristics of the specimens under conventional triaxial and cyclic loading and unloading tests were slightly different with varying confining pressure. Specimens under low confining pressure primarily undergo shear failure, accompanied by a few of tensile cracks and secondary cracks. Under high confining pressure, only one complete shear crack passes through the upper and bottom surfaces of the specimen. Results show that the supporting measures for deep failure of the complete surrounding rock in the deep underground cavern in the sampling location should be primarily designed to prevent shear failure.

\section{Data Availability}

The datasets generated for this study are available from the corresponding author upon request.

\section{Conflicts of Interest}

The authors declare that they have no conflicts of interest.

\section{Authors' Contributions}

Jun Zhao completed the test of hard rock under triaxial and cyclic loading and unloading stress paths. Tan Zhang completed the establishment, solution, and manuscript of the macroscopic failure characteristics of the samples under conventional triaxial and cyclic loading and unloading tests.

\section{Acknowledgments}

This work was financially supported by the National Natural Science Foundation of China (51979268).

\section{References}

[1] X. Heping, F. Gao, and J. Yang, "Research and development of rock mechanics in deep ground engineering," Chinese Journal of Rock Mechanics and Engineering, vol. 34, no. 11, pp. 2161-2178, 2015. 
[2] H. Man-chao, X. He-ping, and P. Su-ping, "Study on rock mechanics of deep mining engineering," Chinese Journal of Rock Mechanics and Engineering, vol. 24, no. 16, pp. 2803-2813, 2005, https://www.researchgate.net/scientific-contributions/YD-Jiang-2084506269.

[3] M.-Y. Wang, Z.-P. Zhou, Q. Qi-Hu et al., "Tectonic, deformation and failure problems of deep rock mass," Chinese Journal of Rock Mechanics and Engineering, vol. 25, no. 3, pp. 448-455, 2006.

[4] X. Heping, "Research framework and anticipated results of deep rock mechanics and mining theory," Engineering Science and Technology, vol. 49, no. 2, pp. 1-16, 2017.

[5] Y.-H. Huang, S.-Q. Yang, W.-L. Tian, W. Zeng, and L.-Y. Yu, "An experimental study on fracture mechanical behavior of rock-like materials containing two unparallel fissures under uniaxial compression," Acta Mechanica Sinica, vol. 32, no. 3, pp. $442-455,2016$.

[6] C. D. Martin and N. A. Chandler, "The progressive fracture of lac du bonnet granite," International Journal of Rock Mechanics and Mining Sciences and Geomechanics Abstracts, vol. 31, no. 6, pp. 643-659, 1994.

[7] C. D. Martin, "Seventeenth Canadian geotechnical colloquium: the effect of cohesion loss and stress path on brittle rock strength," Canadian Geotechnical Journal, vol. 34, no. 5, pp. 698-725, 1997.

[8] T. H. Yang, P. Jia, W. H. Shi, P. T. Wang, H. L. Liu, and Q. L. Yu, "Seepage-stress coupled analysis on anisotropic characteristics of the fractured rock mass around roadway," Tunnelling and Underground Space Technology, vol. 43, pp. 11-19, 2014.

[9] Z. Q. Yin, Z. X. Hu, Z. D. Wei et al., “Assessment of blastinginduced ground vibration in an open-pit mine under different rock properties," Advances in Civil Engineering, vol. 2018, Article ID 4603687, 10 pages, 2018.

[10] Z. Yin, W. Chen, H. Hao et al., "Dynamic compressive test of gas-containing coal using a modified split hopkinson pressure bar system," Rock Mechanics and Rock Engineering, vol. 53, pp. 815-829, 2019.

[11] X.-T. Feng, H.-S. Guo, C.-X. Yang, and S.-J. Li, "In situ observation and evaluation of zonal disintegration affected by existing fractures in deep hard rock tunneling," Engineering Geology, vol. 242, pp. 1-11, 2018.

[12] G. Li, Z. Jiang, C. Lv, C. Huang, G. Chen, and M. Li, "Instability mechanism and control technology of soft rock roadway affected by mining and high confined water," International Journal of Mining Science and Technology, vol. 25, no. 4, pp. 573-580, 2015.

[13] Y. Ming-Qing and S. Cheng-Dong, "Experimental study on strengthening of marble specimen in cyclic loading of uniaxial or pseudo-triaxial compression," Chinese Journal of Solid Mechanics, vol. 29, no. 1, pp. 66-72, 2008.

[14] S. Zhang, S. F. Cox, and M. S. Paterson, "The influence of room temperature deformation on porosity and permeability in calcite aggregates," Journal of Geophysical Research, vol. 99, no. 8, pp. 15761-15815, 1994.

[15] J. J. Zhang, W. B. Standifird, J.-C. Roegiers, and Y. Zhang, "Stress-dependent fluid flow and permeability in fractured media: from lab experiments to engineering applications," Rock Mechanics and Rock Engineering, vol. 40, no. 1, pp. 3-21, 2007.

[16] B. Wang, J.-B. Zhu, Y. Ai-Qing, and J. Hu, "Experimental study on mechanical properties of jinping marble under loading and unloading stress paths," Chinese Journal of Rock
Mechanics and Engineering, vol. 27, no. 10, pp. 2138-2145, 2008.

[17] L. Hao-Ran, Y. Chun-He, L. Yu-Lin et al., "Damage evolution and characteristics of ultrasonic velocity and acoustic emission for salt rock under triaxial multilevel loading test," Chinese Journal of Rock Mechanics and Engineering, vol. 35, no. 4, pp. 682-691, 2016.

[18] P. Rui-Dong and J. Yang, W. Peng, "Energy analysis on damage of coal under cyclical triaxial loading and unloading conditions," Journal of China Coal Society, vol. 39, no. 2, pp. 245-252, 2014, https://www.researchgate.net/profile/ Feng_Gao27https://www.researchgate.net/profile/Heping_ Xie3.

[19] X.-B. Yang, H.-M. Cheng, L. Jia-Qi et al., "Energy consumption ratio evolution law of sandstones under triaxial cyclic loading," Rock and Soil Mechanics, vol. 40, no. 10, pp. 3751-3757, 2019.

[20] Z. C. Tang, Q. Z. Zhao, and J. Peng, "Effect of thermal treatment on the basic friction angle of rock joint," Rock Mechanics and Rock Engineering, vol. 53, no. 4, pp. 1973-1990, 2020.

[21] Z. T. Bieniawski and M. J. Bernede, "Suggested methods for determining the uniaxial compressive strength and deformability of rock materials," International Journal of Rock Mechanics and Mining Sciences, vol. 16, no. 2, pp. 135-140, 1979.

[22] X. Shu-Fang and Y. Shu-Bi, Rock Mechanics, Geological Publishing House, Beijing, China, 1986.

[23] Y. Ming-qing, S. Cheng-dong, and X. Tao, "Loading or unloading process in axial direction and young's modulus of rock specimen," Chinese Journal of Geotechnical Engineering, vol. 23, no. 5, pp. 588-592, 2001.

[24] Z. Ze-Qi, S. Qian, L. Xian-lun, and Z. Zhang, "Study on crack initiation mechanism of three gorges granite," Chinese Journal of Rock Mechanics and Engineering, vol. 26, no. 12, pp. 2570-2575, 2007. 